Southern Illinois University Carbondale

OpenSIUC

Working Papers

Political Networks Paper Archive

$12-4-2012$

\title{
Multiplex Networks and Interest Group Influence Reputation: An Exponential Random Graph Model
}

Michael T. Heaney

University of Michigan, mheaney@umich.edu

Follow this and additional works at: http://opensiuc.lib.siu.edu/pn_wp

\section{Recommended Citation}

Heaney, Michael T., "Multiplex Networks and Interest Group Influence Reputation: An Exponential Random Graph Model" (2012). Working Papers. Paper 67.

http://opensiuc.lib.siu.edu/pn_wp/67

This Article is brought to you for free and open access by the Political Networks Paper Archive at OpenSIUC. It has been accepted for inclusion in Working Papers by an authorized administrator of OpenSIUC. For more information, please contact opensiuc@lib.siu.edu. 


\title{
Multiplex Networks and Interest Group Influence Reputation: An Exponential Random Graph Model
}

\author{
Michael T. Heaney ${ }^{\mathrm{a}^{*}}$ \\ a Organizational Studies Program and Department of Political Science, University of Michigan, \\ United States
}

\begin{abstract}
Interest groups struggle to build reputations as influential actors in the policy process and to discern the influence exercised by others. This study conceptualizes influence reputation as a relational variable that varies locally throughout a network. Drawing upon interviews with 168 interest group representatives in the United States health policy domain, this research examines the effects of multiplex networks of communication, coalitions, and issues on influence reputation. Using an exponential random graph model (ERGM), the analysis demonstrates that multiple roles of confidant, collaborator, and issue advocate affect how group representatives understand the influence of those with whom they are tied, after accounting for homophily among interest groups.
\end{abstract}

\section{Keywords}

Multiplexity; Influence; Reputation; Interest groups; United States health policy; Exponential random graph model

\section{Highlights}

- Interest group influence reputations vary locally in multiplex networks.

- Gossip plays a key role in reducing uncertainty about influence reputation.

- Communication, coalitions, and issue networks matter for influence reputation.

- Groups play multiple roles of confidants, collaborators, and issue advocates.

- Communication networks an especially strong predictor of influence reputation.

* 722 Dennison Building, 500 Church Street, Ann Arbor, MI 48108, United States. Tel. +1 2022363369. E-mail address: mheaney@umich.edu 


\section{Introduction}

Relatively little in the American political system is accomplished purely through the exercise of formal authority. In a system defined by multiple veto points and animated by a swath of interested actors, most policy changes are effected by the subtleties of influence. In this world, a reputation for influence is a valuable asset. As a result, public policy scholars have long sought to understand the development of influence reputations and how these reputations matter for politics (see, inter alia, Banfield, 1961; Beritelli and Laesser, 2011; Fernandez and Gould, 1994; Gamson, 1966; Heaney, 2006; Laumann and Knoke, 1987; Leifeld and Schneider, 2012; Wolfinger, 1960).

The distribution of influence reputation is a particular concern in the world of interest group politics (Hojnacki et al. 2012; Smith 1995). Since interest groups lack formal powers, they depend entirely on influence in order to attain their goals. Thus, gossip about which interest groups are influential readily flows through political networks. Research in this area stresses the emergence of consensus about who the influentials are in a network (Laumann and Knoke, 1987: 159). This perspective leads scholars to model an interest group's influence reputation as a single quantity (Leifeld and Schneider, 2012; Fernandez and Gould, 1994; Heaney, 2006). According to this view, an interest group becomes known as having a particular level of influence within a network, which can be explained by the stable characteristics of interest groups and their positions in political networks.

Some interest groups are indeed renowned as influential throughout a network, while others are universally ignored as irrelevant. However, we observe that a common feature of many reputations is that they are fragmented and varied throughout a network (Beritelli and 
Laesser, 2011; Gondal, 2011; Lang and Lang, 1988; Price and Gioia, 2008). Any actor may have a strong reputation in one crowd and a weaker reputation within another. Is it possible to account for this variation using models of influence reputation?

This article argues that the embeddedness of interest groups in multiplex networks is an important explanation for variation in interest group influence reputations. Interest groups participate in and learn about the political process through their communication with other groups, collaboration in coalitions, and advocacy in issue areas. As a group engages in communication, collaboration, and issue advocacy, its performance of multiple roles is visible to other interested observers that use this information to make judgments about the group's contribution (positive or negative) to policy debates. Thus, examining the multiple ways in which interest groups are connected and disconnected helps to account for how their representatives see and think about the community of which they are a part, as well as how they are seen by that community.

This research is based on personal interviews conducted in 2003 with representatives of 168 interest groups working in Washington, DC on national health policy. It models influence reputation in this network as a function of three overlapping networks (Communication, Coalition Overlap, and Issue Overlap) using the exponential random graph model (ERGM) approach, controlling for homophily among interest groups. The results show that who cites whom as influential depends, in part, on connections through these networks. The article concludes by discussing the implications of these results for interest group politics and by suggesting future research on multiplexity, reputation, and dynamics in political networks. 


\section{The Nature of Influence Reputation}

Interest group representatives want to know which actors exert influence over the policy process, but they are uncertain about which actors actually exert influence. This uncertainty exists because of incomplete information, causal complexity, and the large volume of activities in the policy process. First, uncertainty due to incomplete information exists because much of the relevant action in the policy process takes place behind the scenes (Birnbaum, 1992; Birnbaum and Murray, 1987). Lobbyists meet privately (or semi-privately) with policy makers to frame policy arguments, demonstrate grassroots relevance, offer inducements, and occasionally make threats. Stories of what happens in these meetings sometimes leak to a broader audience. But, since no one can know exactly what is said and done in all these situations, it is hard to be certain about who is wielding influence effectively and who is not.

Second, uncertainty due to causal complexity exists because there are many actors in the policy process and many potential paths to influence. Just because an actor supported (or opposed) a policy that was ultimately enacted (or defeated) does not mean that the actor was a root cause of the outcome (Bachrach and Baratz, 1962; Dahl, 1957). Policy outcomes may be caused by institutional rules, demographic changes, critical events, or any of a number of factors that extend beyond the actions of any one actor (Patashnik, 2008). Policy is made through the complex interaction of executive branch officials, legislators, interest groups, think tanks, media, citizens, and other actors (Baumgartner et al., 2009). Even if an interest group appears to exert influence over policy, it is difficult to know whether it is, in fact, a root cause of a particular policy outcome. 
Third, even if interest group representatives were to have complete information about a set of actors and understood perfectly the causal processes that lead them to influence the policy process or not, they would possess uncertainties about influence due to the large volume of actors and events in the policy arena. In recent years, approximately 10,000 bills have been introduced in each two-year session of Congress (Tauberer, 2011). In 2011, there were 12,633 registered lobbyists in Washington, DC (Center for Responsive Politics, 2012). It is impossible for anyone to follow it all. Thus, as interest group representatives may have confidence about the nature of influence possessed by some, but not all, of the other actors in policy process.

Interest group representatives want to reduce their uncertainty about who is influential. Knowledge about influence helps them to better anticipate outcomes in the policy process and to strategically calibrate their responses to emerging events (Krackhardt, 1990; Simpson et al., 2011). For example, if an actor is believed to be influential, then its actions (or inactions) might be viewed as likely to prompt policy change (or stasis); if the actor supports a proposed policy, that policy might have a greater chance of moving forward; if the actor fails to support a proposed policy, then that policy might have a lesser chance of success. Interest group representatives may rely on these expectations, in part, to determine whether they should guide their group's resources toward attempting to support or block the proposed policy.

To reduce their uncertainty about influence, interest group representatives continually gossip about who is influential (Burt 2005; Dunbar, 2004; Ellwardt et al., 2012). Much of this gossip takes place in private conversations among lobbyists, in coalitions, in issue forums, and in other opportunities to connect with participants in the policy process. Gossip is facilitated by a wide range of specialized publications that follow the policy process with an insider 
perspective, such as National Journal Daily, Roll Call, The Hill, and Politico, as well as policyarea-specific forums, such as the Daily Health Policy Report. From this gossip, reputations are born. Political actors then use reputation as an information shortcut in making judgments about influence.

Since reputations spread through gossip, they diffuse unevenly through networks. Some interest groups are nearly universally renowned as being influential. For example, the National Rifle Association, the American Israel Public Affairs Committee, and the United States Chamber of Commerce are widely known to be influential, even by those who are not close observers of politics. However, other organizations build their reputations for influence in more limited social circles (Gondal, 2011). This continuum from peer recognition to universal renown is a common pattern in reputational systems (Lang and Lang, 1988). Empirical studies have demonstrated this pattern in diverse phenomena from tourism (Beritelli and Laesser, 2011) to corporate image management (Price and Gioia, 2008).

It is not necessary to make strong claims about the extent to which reputations are "deserved"; that is, do "truly influential" actors have strong reputations for influence while, "truly non-influential" actors have weak reputations for influence? Reputations are sometimes well deserved and at other times are undeserved. Sometimes influential actors are recognized and respected, while at other times they remain undetected behind the scenes. Sometimes non-influential actors are summarily dismissed, while at other times they are mistakenly thought to be important players. At minimum, there is a loose linkage between reputation and actual influence (Galaskiewicz, 1979; Laumann, Marsden, and Galaskiewicz 1977: 626; Weible 
2005). ${ }^{1}$ As long as such a linkage exists, policy actors will seek out more reliable gossip and attempt to make inferences from this noisy signal.

As long as reputations are assumed by policy actors to contain an element of truth, then reputations serve as a resource for those that possess them (Gamson, 1966). As Philip Leifield and Volker Schneider (2012: 3) note, "perceived influence of a potential alter is a sign of high quality, either in terms of its information potential or as a powerful ally" (see also Smith, 1995; Weible, 2005). If Actor A believes that Actor B is influential, then B may have a greater likelihood of soliciting A's cooperation on a range of projects. That is, A may behave "as if" $\mathbf{B}$ is influential (Wedeen, 1998: 519). Thus, B may be able to translate its influence reputation imperfectly and incompletely - into actual influence. These mechanisms make the distribution of influence reputation a worthy subject of scholarly inquiry, just as it is frequently the object of interest group attention.

\section{A Theory of Multiplex Networks and Influence Reputation}

Multiplex networks exist when actors are connected through more than one type of socially relevant tie (White, 2008: 38). In a multiplex network, different ties reflect the diverse roles played by participants in the network. For example, a set of adult friends may have ties that can be classified as kin, neighbor, and/or coworker (Verbrugge, 1979). Or, a set of coworkers may have ties that can be classified as authority relations, friendship, and/or exchange of advice (Krackhardt, 1992). Multiplex networks are particularly consequential when

\footnotetext{
${ }^{1}$ Stuart, Hoang, and Hybels (1999) make a similar point in another empirical context in their analysis of young, venture-capital-backed biotechnology firms. They show that start-up firms that receive endorsements from prominent exchange partners experience a kind of "interorganizational certification" that enables them to outperform their competitors. List (2006) also demonstrates the effect of reputation in influencing actual decisions in laboratory and field experiments in the market for sports cards.
} 
they overlap and interact to create processes that cannot be explained by a single network alone. Along these lines, previous research demonstrates that multiplexity is critical to diverse phenomena, such as the mobilization of social movements (Gould, 1991), the consolidation of political power (Padgett and Ansell, 1993), the emergence of trust in economic relationships (Granovetter, 1985), the creation of social bonds within civic networks (Baldassarri and Diani, 2007), and the organization of party coalitions (Grossman and Dominguez, 2009).

The principal argument of this article is that multiplex networks are critical for interest group representatives as they resolve uncertainty about which other interest groups are influential in the policy process. This argument is based on two premises. First, when interest groups are connected with one another in multiplex networks, they are more likely to receive information about one another than they are to receive information about those from whom they are disconnected. These connections enable interest group representatives to learn about the behind-the-scenes actions of their alters, which reduces uncertainty about their alters' degree of influence. Thus, interest group representatives may be more likely think of their alters as influential than to think of those with whom they are not tied as influential.

Second, interest groups are connected with myriad other actors in the policy process. A challenge they face is how to sort through these connections to determine which ones are genuinely important. The overlapping connections provided by multiplex networks create redundancies that help to reduce uncertainties about influence (Landau, 1969). Information that travels through multiple paths may be more likely to be trusted than information that comes only from a single source (Grannovetter, 1985), thus reducing uncertainty. Further, multiplex networks represent the conflux of multiple role structures (Padgett and Powell, 
2012), so multiplexity reduces uncertainty by allowing ego to see the actions of its alters across multiple roles. As a result, interest groups may be more likely to think of those with whom they have multiple connections as influential than to think of those with whom they have one or zero connections.

I argue that there are three types of networks that are especially important in shaping the way that interest group representatives think about influence: Communication networks, Coalition Overlap networks, and Issue Overlap networks. These networks reflect the distinct, but overlapping, roles that interest groups play as confidants, collaborators, and issue advocates. First, Communication networks provide the channels through which gossip flows. Communication network ties exist when interest group representatives confide directly with one another in person or through electronic media, such as telephones or e-mail. The nature and speed of information diffusion in these networks depends on the strength of ties between actors (Granovetter, 1973). Interaction in these networks has the potential to breed familiarity and trust (Carpenter et al., 2003, 2004). As trust builds, communication partners may assume the role of confidants, thus allowing more sensitive and valuable information to pass through the network (Krackhardt, 1992). I expect that interest group representatives are less uncertain about the activities of those who they confide regularly, giving them a more precise estimate of the influence of these alters. With a more precise estimate of influence, representatives are more likely to indicate that an alter is influential when it is, in fact, influential. Hence, this research tests the hypothesis that the likelihood that an interest group representative thinks of another group as influential increases as the strength of its contact with that group in Communication networks increases. 
Beyond the ad hoc, direct relationships that interest groups form in Communication networks, lobbying coalitions are a routine way for interest groups to collaborate when they share interests with other groups (Hojnacki, 1998; Holyoke, 2011; Hula 1999; Loomis, 1986; Nelson and Yackee, 2012). A lobbying coalition exists whenever two or more interest groups explicitly decide to collaborate in advocating for a policy position on which they mutually agree. $^{2}$ By joining coalitions and assuming the role of collaborator, interest groups expose their inner workings to their coalition partners. I argue that the overlapping memberships created by participation in these coalitions form a second important network among interest groups, which I call Coalition Overlap networks.

Coalition Overlap network ties exist when two interest groups share membership in at least one lobbying coalition. Some interest groups join numerous coalitions on a wide range of issues, while some interest groups join few (if any) coalitions (Hojnacki, 1997). The strength of overlapping ties in these networks vary depending on the number of coalitions that the two interest groups have in common. Conceptualizing networks in this way-based on common group affiliation - is a long-standing practice in the networks field, beginning with Breiger's (1974) classic examination of eighteen southern women who attended fourteen parties. Applications of affiliation networks to political questions include Porter et al.'s (2005) analysis of committee co-memberships in the U.S. House of Representatives, Fowler's (2006) study of

\footnotetext{
${ }^{2}$ Readers familiar with the European political context may be inclined to prefer a slightly broader definition of the concept of "coalition," perhaps including cases where groups are on the same side of an issue, but do not coordinate their work directly with one another. The definition that I am using, however, is consistent with its use in the American political context. See Mahoney (2008) for an excellent analysis of the differences between the ways that coalitions work in the United States versus Europe. In particular, coalitions are relied on more frequently in the United States and tend to be comparably more professionalized there. Of course, this observation in not intended to imply that the organizational structures of coalitions are homogenous in the United States. Indeed, coalitions may be small or larger, hierarchical or decentralized, formal or informal, or vary structurally in any number of ways.
} 
legislative bill co-sponsorship, Heaney and Rojas's (2007) model of mobilization by antiwar activists, Grossman and Dominguez's (2009) exploration of common interest group endorsements of electoral candidates, and Murdie and Davis's (2011) mapping of common issue activity by international nongovernmental organizations.

Because Coalition Overlap networks are based on affiliations, rather than on direct contacts between groups, they require a different interpretation than do communication networks. Coalitional collaboration often brings groups into close contact with one another, though some coalitional relationships are arms-length partnerships where some interest groups extend their name and support to the coalition without necessarily becoming involved in its day-to-day operations (Hula, 1999). Members of a coalition need not interact with one another directly, especially if the size of the coalition is large or if its organizational structure is hierarchical in nature. Thus, being tied to another interest group through coalition overlap reduces uncertainty about influence reputation differently than do ties in communication networks.

Actor A's judgments about its coalition partner, Actor B, may be formed in the absence of any direct interaction between $\mathbf{A}$ and $\mathbf{B}$. Coalition overlap allows interest groups to observe whether their collaborators attempt to set the coalition's agenda, the extent to which they contribute to its work, and whether their partners get in their way or not. Through coalition meetings, e-mail listservs, and publicly-staged events, interest group representatives observe their partners' actions or inactions in coalition settings. Further, coalitions create an institutional setting for interest group representatives to gossip about their collaborators. If Actors A, B, and C are in a coalition together, then A may form its judgments about B, in part, 
through gossiping with $\mathbf{C}$ about $\mathbf{B}$. Such opportunities are more plentiful as the number of coalitions that $\mathbf{A}$ and $\mathbf{B}$ have in common expands. Hence, this research tests the hypothesis that the likelihood that an interest group representative thinks of another group as influential increases as the number of coalition memberships that they have in common increases.

A third way that interest groups are networked with one another is through common involvement in the same issue areas, which I call Issue Overlap networks. Two interest groups are tied in an issue overlap network when they work on at least one issue in common. These network ties become stronger as the number of common issues rises. Like Coalition Overlap networks, Issue Overlap networks are affiliation networks - as described by Breiger (1974) - so they also require a different interpretation than is provided for Communication networks. Interest groups that are linked in Issue Overlap networks may communicate directly with one another and work together on policy issues, but it is also possible that they neither communicate directly with one another nor work on the same side of an issue. Indeed, interest groups that are linked in an Issue Overlap network may be adversaries on an issue. Yet, issues serve as a common basis for interest groups to establish niches and forge distinct identities (Browne, 1990; Heaney, 2004). Issue-oriented policy communities promote opportunities for information sharing within issue areas, such as policy conferences, electronic bulletin boards, and issue-focused periodicals. As a result, interest groups are able to closely monitor both allies and adversaries in their roles as issue advocates when then have overlapping issue niches. These processes give rise to "issue networks," as Hugh Helco (1978) noted more than three decades ago, in which the participants acquire known reputations based on their involvement in issues. 
I argue that as the number of overlapping issues between two groups increases, issuebased monitoring reduces the amount of uncertainty than interest groups have about one another's influence. Thus, this research tests the hypothesis that when two interest groups have a greater number of overlapping issues in common, then they are more likely to observe one another as active in issue-based communities and, consequently, to think of each other as influential than when they have fewer overlapping issues in common.

A fundamental premise underlying the hypotheses advanced here - that interest groups that are more closely connected in multiplex networks have less uncertainty about one another's influence levels - may appear to be at odds with other scholarship on the subject of multiplexity. Most notably, John Padgett and Christopher Ansell (1993) contend that the presence of multiplex networks increases uncertainty of strategic actors engaged in "robust action." However, the appearance of difference is engendered by distinctions in the cases at hand. The present study examines the uncertainty with which egos make assessments in ability of alters to influence a system, whereas Padgett and Ansell examine uncertainty about exactly which moves alters will make. But, both perspectives may hold simultaneously: multiplexity may reduce uncertainty about the fact that an alter is influential, while at the same time raising uncertainty about how exactly the alter will wield that influence. Hence, it is important to underscore that the hypotheses tested here apply to the relationship between multiplexity and influence reputation. Multiplexity may have different kinds of effects on other political phenomena. 


\section{Homophily as an Alternative Explantion}

In order to assess the importance of multiplex networks in shaping influence reputations, it is essential to account for alternative explanations for how actors think about influence. Perhaps the most important alternative explanation is homophily, which is the idea that actors form social ties with one another when they are similar in important ways (Heaney et al. 2012; Leifeld and Schneider, 2012; McPherson et al., 2001). While interest group representatives may draw upon interaction in multiplex networks when forming impressions of influence, it is also possible that they look to those that are similar to themselves in important respects and assume that those actors are influential, irrespective of who they interact with. Actors use these kinds of comparisons to make sense of their working environments (Lawrence, 2006). For example, when two interest groups have the same organizational form - perhaps they are both trade associations or citizens advocacy groups - then their representatives better understand each other's missions, governance, and methods of advocacy because of their isomorphism with one another (DiMaggio and Powell, 1983). As interest group representatives understand one another better, they may be more likely to cite one another as influential, irrespective of who they interact with. Failure to consider homophily may lead analysts to overestimate social influence effects in network data (Fowler et al., 2011; Noel and Nyhan, 2011).

It is important to recognize that homophily offers an explanation fundamentally different than multiplexity for interest groups' assessments. Homophily assumes that ego's assessments are based on alter's individual qualities, not based on the shared relationship between ego and alter. Multiplexity assumes, however, that ego assesses alter's influence by 
observing alter's performance of three roles (confidant, collaborator, and issue advocate) because of shared network ties.

In order to account for homophily in the formation of interest group reputation, I hypothesize that interest group representatives are more likely to think of other groups as influential when those groups share significant political characteristics with the representative's organization. These characteristics include organizational type, partisanship, significant lobbying expenditures, campaign spending through Political Action Committees, independent expenditures, and office location, all of which have been associated with levels of interest group influence in previous research (Heaney 2006).

\section{Research Design}

In order to understand influence reputation, this study focuses on networks among interest groups in the U.S. health policy domain. The data are drawn from interviews conducted by the author in 2003 . Focusing on a single policy domain ensures that the major actors in question are connected within a common network. Addressing health policy, in particular, allows analysis of a broad field of diverse actors from multiple ideological points of view and substantive foci. Indeed, the health policy domain contains issues that have high salience (e.g., universal health insurance) and low salience (e.g., the scope of practice for nurse anesthetists), as well as issues that are highly partisan (e.g., the creation tax-exempt health savings accounts) and bipartisan/nonpartisan (e.g., funding for medical research on Alzheimer's disease). Active participants in the domain include unions, veterans' organizations, citizens' groups, professional societies, trade associations, associations of government officials, think 
tanks, foundations, and other interests that may have some role in the production, consumption, financing, and/or regulation of health care. The breadth and complexity of the health policy domain ensures that the research reflects the forces active in American politics generally, even though health policy is not a typical domain. In particular, health politics are more amenable to redistributive arguments and moral claims than are politics in other domains, and bureaucratic agencies are more engaged in the administration of health policies than they are in other policy areas (Carpenter 2012).

Since a wide variety of interest groups have some involvement in health policy debates, a challenge of the research design was to select a diverse set of interest groups that would be large enough to include the major players in all key debates, but small enough to be included in a single study. An important practical constraint on the size of the sample selected was that a representative from each interest group would be shown a complete list of all the interest groups in the study. The list must be short enough that representatives can review the names of all interest groups within a few minutes.

Following the approach to boundary specification recommended by Laumann et al. (1989), the most active interest groups in the network were determined based on four sources. First, the federal lobbying reports of interest groups were examined if they indicated that the interest group lobbied on health care, Medicare and Medicaid, or medical research issues from 1997 to 2002 (U.S. Senate, Office of Public Records, 2002). Interest groups from this list were ranked based on their reported federal lobbying expenditures. Second, interest groups were ranked based on the number of times that they testified at health-policy-related hearings on Capitol Hill from 1997 to 2002 (LexisNexis, 2002). Any interest group that ranked among the 
top 50 groups on either of the first two lists, or among the top 100 groups on both lists, was included in the study. Third, interest groups with a long history of involvement in health policy debates were considered by including all interest groups that appeared in Laumann and Knoke's (1987) study of the health policy domain. Fourth, a preliminary list of interest groups, which was compiled based on the first three sources, was circulated to a panel of experts from academia and the policy world to solicit additional recommendations. Any interest group recommended by at least two experts was included in the study. This procedure led to the identification of 171 interest groups as the "most active" groups in the health policy domain.

Representatives of each of the 171 interest groups were contacted in 2003 to request an anonymous interview. High-level representatives from 168 of these groups were ultimately interviewed, which constitutes the sample for the statistical analysis reported in this article. The majority of interviews were conducted with representatives holding the title of "Director of Governmental Affairs" (or equivalent), though some interviews were conducted with higherlevel representatives (e.g., Executive Director, Vice President) or lower-level representatives (e.g., Assistant Director of Congressional Affairs). Interviews were conducted in person for 163 interest groups and by telephone for 5 groups. A premium was placed on conducting interviews in person with high-level actors in order to ensure the collection of quality data on influence reputation and network ties.

Network data on Influence, Communication, Coalition Overlap, and Issue Overlap were derived by combining interviews and archival data sources. Interview questions were adapted from the interview instrument implemented by Lauman and Knoke (1987: 413-500). The 
definitions, interview questions, and sources for each of these networks are reported in Table 1.

\section{INSERT TABLE 1 HERE}

\section{Data}

Implementation of the research design outlined in the previous section led to the collection of data on four networks with varied structures. The properties of these networks, reported in Table 2, depend both upon their empirical structures, as well as how the networks are defined and measured. Two of the networks are directed (Influence and Communication), while the other two are undirected (Coalition Overlap and Issue Overlap). Three of the networks are valued (Communication, Coalition Overlap, and Issue Overlap), while one is binary (Influence). Influence has the lowest mean degree (20.429), the lowest density (0.121), and highest centralization (0.113) in the set, reflecting the fact that interest group representatives are relatively reserved in terms of who they name as influential actors. In contrast, Issue Overlap has the highest mean degree (127.357), highest density (0.757), and the lowest centralization (0.002), reflecting the fact that about three-fourths of the interest groups have at least one issue in common with one another. Significant variation in this network comes from the edge values, which represent the number of issues that interest group dyads have in common. On average, an interest group dyad has 2.573 issues in common, varying from 0 to 15 common issues $(\sigma=2.527)$. Communication and Coalition Overlap are moderately more dense, have higher degree, and are less centralized than Influence, though they are closer to the Influence network on these measures than to the Issue Overlap network. Both Communication 
and Coalition Overlap have valued edges, which are an especially important aspect of variation in the Coalition Overlap network.

\section{INSERT TABLE 2 HERE}

The principal phenomenon of interest in this article is the citation pattern in the Influence network, which is graphed in Figure 1a. This network has a core-periphery structure, with the most influential interest groups positioned toward the center of the network and the least influential groups positioned toward the periphery. A clearer understanding of this network can be gained by examining the influence citations received by two exemplar nodes. Figure $1 \mathrm{~b}$ reports the citations received by one of the leading actors in the network. This actor has a reputation for influence that cascades throughout the network such that most other actors cite it as influential. This actor is cited as influential by friends and enemies alike; by those with which it works closely and by those with which it has no relationship. In contrast, Figure $1 c$ reports the citations received by an actor with a narrower influence reputation. Not only does it receive fewer citations than the leading actor (which is true by definition), but its citations come from other actors that are close to it in the network. It has built a local reputation for influence. Some of the other interest groups with which it is connected see it as influential, but it is not known as important beyond this community.

\section{INSERT FIGURE 1 HERE}

While both the leading actor (Figure 1b) and the locally influential actor (Figure 1c) networks are ideal-typical examples, the citation patterns in the Influence network overall tend to look more like Figure $1 \mathrm{c}$ than like Figure $1 \mathrm{~b}$. That is, the Influence network tends to be 
composed of more interest groups with local influence reputations than groups with global influence reputations (Gondal, 2011).

If influence reputations develop locally, then information on local social structures are important to understand patterns of influence. Gossip is a key mechanism that helps to create these local structures. As participants in the network gossip about their assessments of influence - for example, which interest group made all the difference in passing a recent bill or which group is all talk and no action - these assessments become correlated with the network structure. Examining the multiple overlapping networks in which interest groups are embedded helps to reveal these network structures.

In order to begin to understand the relationships among these overlapping networks, the correlations among them were calculated using the Quadratic Assignment Procedure (Krackhardt, 1987) and are reported in Table 3. The results show that the Influence network is significantly correlated with each of the other three networks, with the highest correlation existing with the Communication network (0.140). Each of the other networks is correlated with the others, with the highest correlation existing between Communication and Coalition Overlap (0.367). Given the significant, positive correlations among Communication, Coalition Overlap, and Issue Overlap, it is possible that these correlations may partially suppress the relationships between these networks and the influence network in the ERGM below.

\section{INSERT TABLE 3 HERE}

Further understanding of these overlapping structures can be discerned by calculating concordance in citations across networks. The first part of Table 4 reports the conditional probability that if an interest group dyad is tied in one network that it is also tied in another 
network. The first column of Table 4 indicates that if $\mathbf{A}$ cites $\mathbf{B}$ in the Communication network then there is a 0.210 probability that $\mathbf{A}$ also cites $\mathbf{B}$ in the Influence network. If $\mathbf{A}$ is tied with $\mathbf{B}$ in the Coalition Overlap network, then there is a 0.163 probability that A cites B in the Influence network. If $\mathbf{A}$ is tied with $\mathbf{B}$ in the Issue Overlap network, then there is a 0.133 probability that A cites B in the Influence network. The second, third, and fourth columns of the table similarly reflect conditional probabilities that $\mathbf{A}$ and $\mathbf{B}$ are tied in the Communication, Coalition Overlap, and Issue Overlap networks. These probabilities are increasing from left to right because the density of the reported networks is increasing from left to right. These results underscore the local patterns of reputation in the network. If an interest group is tied with another in the Communication, Coalition Overlap, and/or Issue Overlap network, then there is a high probability that the interest group's representative cites that alter in the Influence network.

The second part of Table 2 reports the higher-order concordance of Communication, Coalition Overlap, and Issue Overlap with Influence. The table contains conditional probabilities that if an interest group dyad is tied in two or three networks then it is also tied in the Influence network. Consistent with the expectation that increased overlap in multiplex networks reduces uncertainty about influence, the probability of concordance with influence is higher in cases where dyads have at least two ties in common than when they have at least one tie in common. Finally, the highest probability of concordance with influence occurs when the dyad is tied in all three networks. Specifically, if A is tied with B in all three networks for Communication, Coalition Overlap, and Issue Overlap, then there is a 0.237 probability that A cites B in the Influence network. 
To visualize these overlapping networks, a random sample of 25 nodes from the Influence network is graphed in Figure 2. Only Influence citations (red lines) are graphed in Figure 2a and only Communication citations (blue lines) are graphed in Figure $2 \mathrm{~b}$. The overlap between these two networks is visualized in Figure 3c. The black lines represent dyads in which both Influence citations and Communication citations were reported. Clearly, Influence and Communication do not perfectly predict one another. Yet, the graph indicates a significant tendency for actors to cite as influential the other actors with whom they communicate.

\section{INSERT FIGURE 2 HERE}

In addition to collecting network data, I compiled data on several interest group attributes to account for the possibility that interest groups cite one another as influential if they share important characteristics. First, I classified the groups in the study based on eight mutually exclusive organizational types: academic organizations (5.35\%), citizens' advocacy organizations (21.43\%), associations of government officials (4.76\%), nonmember advocacy organizations and foundations (5.95\%), professional societies (27.38\%), trade associations (27.38\%), labor unions (4.76\%), and veterans organizations (2.98\%). The variable Same Organizational Type takes the value of 1 if two interest groups match on this variable, 0 otherwise. Second, I determined the partisanship of groups based on interviews with 95 congressional staff (48 Republicans and 46 Democrats, proportionately split based on control of Congress in 2003). On average, interest groups had about one (0.940) more regular, reliable lobbying tie with Republicans than with Democrats. Interest groups varied from having 16 more ties with Democrats to having 17 more ties with Republicans ( $\sigma=4.997)$. The variable 
Similar Partisan Ties takes the value of 1 if two interest groups were within three points of one another on this measure, 0 otherwise.

A third measure of similarity is the organization's level of lobbying activity.

Approximately one quarter (23.67\%) of the interest groups in this study reported spending one million dollars or more on lobbying in 2003 (U.S. Senate, Office of Public Records, 2003). The variable Similar Lobbying Activity takes the value of 1 if the two groups both spent a million dollars or more on lobbying in 2003,0 otherwise. Fourth, $40.24 \%$ of interest groups in the study made expenditures through a political action committee (PAC) in 2001-2002 (Center for Responsive Politics, 2003). The variable Both Have PAC takes the value of 1 if the two groups both made PAC expenditures in $2001-2002,0$ otherwise. Fifth, $8.88 \%$ of interest groups in the study made independent expenditures in political campaigns in 2000 (Goldstein et al., 2002). The variable Both Make Independent Expenditures takes the value of 1 if the two groups made independent expenditures in 2000,0 otherwise. Sixth, $52.07 \%$ of interest groups in the study had offices in the downtown area of Washington, DC (colloquially referred to as "K Street"). The variable Both Have Downtown Office takes the value of 1 if the two groups both had a downtown office, 0 otherwise.

In order to obtain a more systematic understanding of the relationship between these overlapping tendencies and interest group characteristics, it is necessary to develop a statistical model that predicts the local patterns of citation observed in the Influence network using data from each of the relevant political networks and shared interest group attributes. The next section introduces the ERGM approach, which yields a model that meets this objective. 


\section{An Exponential Random Graph Model (ERGM)}

The ERGM approach to network analysis treats the ties in a network as a random variable to be explained by a statistical model. The "core statistical challenge" of the ERGM approach is to model the dependence among these ties based on the specifications of the modeler (Cranmer and Desmarais, 2011: 66). Conditional dependence exists when the possibility of forming a tie between actor $\mathbf{A}$ and actor $\mathbf{B}$ is affected by the presence or absence of a tie between A or B and a third actor, C (Frank and Strauss, 1986). For example, the possibility that two interest groups may enter into a coalition arrangement with one another depends on the coalitional arrangements that these two actors have already formed. If the two groups are already aligned with competitors of one another, then it may be difficult to forge a coalition. However, if they are aligned with other friendly groups, then a coalition may be cemented more easily. Beyond conditional dependence, more complex dependence structures may be present in the data. Ties may be dependent on one another because of structural properties of a network such as density, reciprocity, transitivity, or edgewise shared partners (Robins et al., 2007; Snijders et al., 2006). The principal advantage of the ERGM approach is its ability to specify these complex dependencies in a statistical model by using both endogenous and exogenous parameters.

This article develops and tests an ERGM for the Influence network. Several endogenous parameters are selected to model dependencies in the network so that the functional form of the ERGM matches the underlying structure of the network data. First, a parameter for edges is included to account for the density of the Influence network. This parameter ensures that the estimated model produces networks with a density equal to the observed density in the 
Influence network; it is the analog of a regression constant term and is a standard parameter in an ERGM. Second, two parameters are included to account for relationships with either one or two edgewise shared partners. These configurations are included in the model because gossip about influence spreads through locally proximate actors, thus engendering network dependencies in influence citations. Entering these parameters ensure that the estimated model produces networks with one- or two-edgewise-shared-partner configurations equivalent to what is observed in the Influence network.

Parameters are included in the model for the indegree and outdegree of each ego. Including these parameters in the model ensures that the degree distribution in the estimated ERGM replicate the degree distribution in the population. The indegree parameter accounts for the overall level of influence reputation for each interest group in the network. It allows for the possibility that information about high-influence groups flows through the network differently than information about low-influence groups; perhaps information about high-influence groups cascades, while information about low-information groups does not. Thus, an ERGM specified to include this parameter does not explain why interest groups attain the level of influence reputation that they do - this level is assumed by the model. Rather, it explains why an interest group receives citations from particular other actors, given a fixed level of influence reputation.

The outdegree parameter accounts for the different thresholds that respondents use in judging influence. The inclusion of this parameter is important because different respondents may operate with different mental models of policy influence or may understand the interview question about influence differently (Wolfinger, 1960). Thus, an ERGM specified to include this 
parameter explains why respondents allocate their influence citations the way that they do, given their propensity for designating actors as influential or not. ${ }^{3}$

Six ERGMs were estimated that include different combinations of exogenous and endogenous parameters. The Baseline Model (1) includes the six homophily variables and the five endogenous parameters described above. Models (2) through (4) include the parameters from the Baseline Model plus one of the networks described above (Communication, Coalition Overlap, or Issue Overlap). These models allow the evaluation of the direct effects of each of the networks of interest on Influence, separate from the potential confounding effects of multicollinearity resulting from positive correlations among these three networks. Model (5) includes all three networks of interest, the six homophily variables, as well as parameters for edges and one and two edgewise shared partners. This model explicitly excludes indegree and outdegree parameters in order to evaluate the extent to which these parameters affect the substantive conclusions drawn from the results. Model (6) is the Multiplex Full Model, which includes the Baseline Model plus all three networks and the five endogenous parameters. These models are estimated using the Markov Chain Monte Carlo (MCMC) estimation technique (Snijders, 2002).

The results of the ERGM estimation are reported in Table 5. For each model and parameter, the table reports the estimated coefficient, (standard error), and [MCMC standard error]. The Baseline Model (1) demonstrates that homophily is a potentially important explanation for the observed pattern of citations in the Influence network. The results indicate

\footnotetext{
${ }^{3}$ In developing the models reported in this article, I experimented with a variety of endogenous parameters, such as parameters for a geometrically weighted degree distribution, a geometrically weighted edgewise shared partner distribution, mutuality, reciprocity, and transitivity. However, I found that these parameters did not provide a good fit for the Influence network.
} 
that interest group representatives are likely to cite as influential other groups that share the same organizational type and substantial expenditures on lobbying. These results also contain the counterintuitive finding that interest groups with PACs are less likely to cite as influential other organizations with PAC, other things equal.

\section{INSERT TABLE 5 HERE}

Models (2) through (4) demonstrate that the Communication, Coalition Overlap, and Issue Overlap networks each explain citations in the Influence network when they are included in the analysis one at a time. In each of these models, Same Organizational Type and Similar Lobbying Activity have positive, statistically significant coefficients, as is the case in Model (1). The variable Both Have PAC does not have the unexpected negative, statistically significant coefficient that appears in Model (1).

Models (5) and (6) simultaneously include Communication, Coalition Overlap, and Issue Overlap networks in the analysis. Both of these models yield positive, statistically significant coefficients for all three networks. There are some differences between the two models regarding differences in the homophily control variables. Model (5), which does not include the indegree and outdegree parameters, produces statistically significant coefficients for Similar Partisan Ties (negative), Similar Lobbying Activity (positive), Both Have PAC (positive), Both Make Independent Expenditures (positive), and Both Have Downtown Office (positive). Model (6), which includes the indegree and outdegree parameters, produces statistically significant coefficients for Same Organizational Type (positive), Similar Lobbying Activity (positive), and Both Have PAC (negative). 
Comparisons can be made across models using the Bayesian Information Criterion (BIC) in order to determine which model is the best in explaining the observed pattern in the Influence network. The BIC allows the evaluation of improvements in a model after adding new variables while compensating for the fact that adding new variables may affect the likelihood of a model by overfitting alone (Schwarz, 1978). BIC statistics are reported at the bottom of Table 5. The Baseline Model (1) has a BIC of 13,570 , which can be used as a reference point against which to compare Models (2) through (6). Each of Models (2), (3), and (4) offers a reduction of the BIC over Model (1), indicating the superiority of models including networks over the Baseline model. Model (2), which includes the Communication network, has the lowest BIC $(13,479)$ in this subset. Model $(5)$, which includes all three networks but does not include indegree and outdegree parameters, has the highest $\operatorname{BIC}(19,201)$ in the set. Finally, the Multiplex Full Model $(6)$ has the lowest BIC $(13,471)$, suggesting that it is superior to the other models considered in this analysis.

A direct comparison of Models (1) and (6) allows an overall assessment of homophily versus multiplexity as determinants of interest group influence reputation. The results show that the two types of explanations do not compete with one another in a statistical sense. That is, the pattern of significant and insignificant coefficients reported in Model (1) is unchanged in Model (6) when the three network variables enter the equation. Thus, it is consistent with the data to say that both homophily and multiplexity are explanations for the development of influence reputation.

Beyond examining the statistical significance of individual parameters and the BIC statistics, it is also important to examine the overall goodness of fit of the model. To do so, the 
observed data in the Influence network are plotted against the model simulations for four structural characteristics of the network (indegree, outdegree, edgewise shared partners, and triad census), as recommended by Hunter et al. (2008; see also Goodreau et al., 2009). The plots for the Multiplex Full Model (6) are reported in Figure 3. The results indicate that the simulated model provides a very good representation of the observed data, though the fit is not perfect. Almost all of the observed data points, indicated by the dark black line, fall within the 95 percent confidence interval of the simulations, indicated by the gray lines. The fit of the model could be improved slightly by including parameters for specific degree values (e.g., degree $=0$ ). However, such an approach would surely overfit the model to the data. Thus, it is reasonable to have confidence that the Multiplex Full Model (6) generates estimates that well reflect key structural features of the observed network. This analysis validates the choice of the functional form indicated by the endogenous parameters in the model.

The question naturally arises regarding the extent to which the substantive conclusions drawn from the ERGMs are a function of the ERGM methodology itself and how much they are a function of the empirical relationships in the data. One way to evaluate this possibility is to compare the ERGM estimates to those obtained using the Double Semi-Partialing Multiple Regression Quadratic Assignment Procedure (MRQAP) (Dekker et al., 2007). Notable similarities and differences are present in the MRQAP and ERGM procedures. Both procedures address the network autocorrelation problem using randomization. However, ERGM explicitly models the endogenous structure of networks, while MRQAP does not. Also, ERGM allows the inclusion of valued edges in analysis, while MRQAP is limited to dichotomous edges only. Nonetheless, the substantive conclusions drawn from these approaches ought to be generally 
similar if the estimated models are good reflections of the empirical processes under examination.

Five models are estimated using MRQAP and reported in Table 6. Model (7) is an MRQAP version of the Baseline Model, excluding the endogenous parameters and edge values. Models (8), (9), and (10) mirror Models (2), (3), and (4), similarly excluding parameters and edge values. Model (11) matches Models (5) and (6), following the same exclusions as in Models (7) through (10). The results establish that there are no substantive differences among any of the models regarding the direction or significance of the network variables, Communication, Coalition Overlap, and Issue Overlap. While there are some differences exhibited in the pattern of significance displayed in the homophily control variables, these do not affect the conclusions drawn about the importance of multiplexity in these networks.

\section{INSERT TABLE 6 HERE}

The ERGM and MRQAP analysis strongly supports the theory of multiplex networks and interest group influence reputation advanced in this article. The coefficients on all networks variables included in Models (2) through (6) and Models (8) through (11) are statistically significant and positive. These results indicate Communication, Coalition Overlap, and Issue Overlap networks have the expected effect on Influence citations, regardless of the model specification or estimation technique. Models (2), (3), (4), (8), (9), and (10) show that Communication, Coalition Overlap, and Issue Overlap have the expected effect when they are included alone, thus demonstrating that multicollinearity among these networks is not causing these parameters to be falsely significant. Models (5), (6), and (11) establish that multicollinearity does not prevent any of these parameters from being significant. Comparison 
of the results from Models (2) through (6) with the results from Model (8) through (11) reveals that these results are not an artifact of the ERGM methodology, as the same pattern obtains when MRQAP is implemented. ${ }^{4}$

The comparison between Models (5) and (6) is set up to determine the effects of including indegree and outdegree endogenous parameters in the model. These parameters matter importantly for the interpretation of the results. If the degree parameters are included in the model, then the results should be interpreted as the effect of multiplex networks on the likelihood of citing an interest group as influential, holding that interest group's level of influence constant. Thus, this model explains why $\mathbf{A}$ cites $\mathbf{B}$ (as opposed to $\mathbf{C}$ ) as influential, but not B's overall level of level of influence. In contrast, if the degree parameters are excluded from the model, then the results should be interpreted as the effect of multiplex networks on the likelihood of citing an interest group as influential, regardless of the interest group's overall reputed influence. The results reported in Models (5) and (6) indicate that multiplex networks exert a positive, significant effect regardless of whether the degree parameters are included in the model. Multiplexity helps to explain the pattern of influence citations regardless of whether influence is given or explained by the model. Model (6), which includes the degree

\footnotetext{
${ }^{4}$ I considered the possibility that the significant coefficients on the parameters for the Communication, Coalition Overlap, and Issue Overlap networks may depend, in part, on the edge values. Thus, I experimented with a variety of models that relied on dichotomous, rather than valued, edges. These models included: (1) Communication takes the value of 1 only if the edge value is greater than 0 ; (2) Communication takes the value of 1 only if the edge value is greater than 1 ; (3) Coalition Overlap takes the value of 1 only if the edge value is greater than 0; (4) Coalition Overlap takes the value of 1 only if the edge value is greater than 1; (5) Coalition Overlap takes the value of 1 only if the edge value is greater than 2; (6) Issue Overlap takes the value of 1 only if the edge value is greater than 0; (7) Issue Overlap takes the value of 1 only if the edge value is greater than 1; and (8) Issue Overlap takes the value of 1 only if the edge value is greater than 2 . Variation in these models suggests that the incremental effects of additional ties is not likely to be linearly increasing; for example, moving from zero to one tie had a greater marginal effect than moving from one to two ties. However, variations in model specification did not affect the direction or statistical significance of the parameters in the multiplex networks.
} 
parameters, is preferred to Model (5) because of its substantially lower BIC. Model (6) offers a much better fit than Model (5).

The control variables included to account for homophily exhibit variation in their statistical significance. Same Organizational Type is positive and significant in all of the ERGMestimated models, except Model (5), but is not significant in any of MRQAP-estimated models. Similar Partisan Ties is negative and significant in all of the MRQAP-estimated models, but not in the ERGM-estimated models, except Model (5). Similar Lobbying Activity is positive and significant in every model except Model (2), suggesting that interest groups cite one another as influential when they both register high levels of lobbying activity. Both Have PAC is negative and significant in Models (1) and (6), positive and significant in Model (5), and insignificant in all other models. Both Make Independent Expenditures is positive and significant only in Models (5), (7), (9), (10), and (11). Both Have Downtown Office is positive and significant in Models (5), (7), (9), (10), and (11). Variation in the significance of these parameters is likely due to differences among the models in the inclusion or exclusion of endogenous parameters. Because of this variation, it is unwise to draw conclusions about how homophily matters in the allocation of influence citation patterns. Nonetheless, the results establish that the coefficients on the multiplexity parameters are robust to the inclusion of variables intended to account for homophily. Thus, homophily as an alternative explanation for citation patterns does not undermine the validity of the multiplex theory. 


\section{Discussion}

Political actors pay close attention to influence reputation, in part, because actual influence is so difficult to observe unambiguously. Reputation is a useful clue to actual influence. Yet it is a clue that is socially constructed. Studies that have examined influence reputation in the policy process have tended to ignore its socially constructed dimension (e.g., Fernandez and Gould, 1994; Heaney, 2006; Laumann and Knoke, 1987; but see Wolfinger, 1960 for an insightful, though widely ignored, critique). These studies model reputation as an attribute possessed by actors, rather than as the product of the relations that they have with others in a political network. An important reason for this oversight may have been the absence of workable statistical methods to model the network properties of reputation within an explanatory framework. The rise of the ERGM and MRQAP approaches, however, opens the door to remedying this longstanding deficit in the influence reputation literature.

If reputation is essentially an attribute of an actor, then opinions about an actor's reputation should be distributed evenly throughout a network. That is, the probability that any one actor cites another as influential should be strictly a function of the actor's influence level and other structural properties of the network. However, this study documents that that influence reputation has a "local" quality ignored by typical studies on interest group politics. As local actors observe their alters playing a variety of roles in the policy process - as confidants, collaborators, and issue advocates - it reduces their uncertainty about which actors truly matter in making policy and which do not. Thus, it is essential to understand the multiplex networks in which interest groups participate to distill their involvement and influence in the policy process. 
The results of the statistical analysis establish that each of the multiple roles identified in this article are independently significant predictors that an ego cites an alter as influential. At the same time, the results establish that all three networks together matter: When an ego is tied with an alter in all three networks, the probability that ego cites alter as influential is higher than if ego and alter are tied in fewer than all three networks. These findings support the argument that as networks become increasingly multiplex, uncertainty about influence is reduced. Each of the roles that interest groups play - as confidants, collaborators, and issue advocates - are relevant to how their performance is evaluated by their peers. At the same time, the role of confident - played in the communication network - stands out in every model (in Tables 3, 4, 5, and 6) as having the strongest relationship with influence reputation. Thus, while interest groups affect their reputations in all the roles they play, the role of confident is the most reliable and robust way for them to set the tone for how others see their influence potential.

For the purpose of illustration, consider one concrete example from the data of how the multiple roles serve interest groups in practice. The Association of American Medical Colleges (AAMC) built a local reputation for influence by leveraging its roles in multiplex networks. AAMC sought to have a major influence on health policy, though it lacked the extensive resources of leading organizations, such as the American Medical Association (AMA), the Pharmaceutical Research and Manufacturers of America (PhRMA), and AARP (formerly the American Association of Retired Persons). In particular, it sought to influence policies affecting the funding of medical research, especially through research conducted by, and grants provided through, the National Institutes of Health (NIH). To this end, it joined 17 coalitions, well above 
the study's average of 7.911 coalitions per group. In many of these coalitions, such as the Ad Hoc Group for Medical Research, AAMC served as the coalition's convener and sponsor.

By joining and leading multiple coalitions, AAMC became known in the health policy community as a leader and a contributor to public goods. Lobbyists who monitored issues related to medical research were especially well positioned to observe AAMC playing collaborator roles by coordinating coalition activity, ameliorating conflict between contending interests, and representing the medical research community to the broader health field. AAMC's coalition work compensated for its weaker presence in Communication networks and Issue Overlap networks - at least in comparison with leading actors such as AMA, PhRMA, and AARP. By leveraging its position in multiple networks, AAMC was credited by many advocates with helping to dramatically expand the NIH budget. It was cited as an influential organization by 48 of the 167 other interest group representatives that I interviewed. This count did not place it in the top handful of interest groups in the health policy domain, but it did earn well above the network average of 20.429 citations.

Despite the strength of the results reported in the previous section, it also essential to recognize the limitations of the present study. The social processes behind the formation of influence reputation may be more complex than is reflected in the models estimated in this article. First, the four networks examined in this article reflect only a few of the myriad types of ties that connect interest groups to one another. Additionally, interest groups and their representatives are connected though participation in the campaign finance system, relationships established during previous coalitions or spells of prior employment, alumni ties, and more. These networks reflect other critical roles played by interest group representatives. 
The analysis reported in this article demonstrates that multiplex networks matter, but does not establish conclusively that the networks identified in this research are the only networks that matter. Given this limitation, investigation into other sources of multiplexity is an important direction for future research.

Second, the need to define the boundaries of the network in a manageable way restricted the scope of this investigation to 168 interest groups in health policy. While such boundary specification is essential to conduct network analysis, the real world of public policy is not artificially constrained according to narrowly defined policy areas. Domains of policy may overlap and intersect in ways that are not reflected in this research. Also, multiplexity may work differently in a highly complex policy domain, such as health policy, than it does in a less extensive and simpler domain, such as transportation. This research establishes that multiplexity matters under at least some important circumstances. Yet it may not matter under other circumstances. Given these concerns, future studies should investigate the effects of networks that overlap policy domains and how multiplex networks may vary in their consequences from domain to domain.

Finally, it is possible that the direction of causality flows, in part, in the opposite direction of what is posited in this article. The models estimated here assume that interest groups form ties in the Communication, Coalition Overlap, and Issue Overlap networks and, subsequently, their representatives use these networks to develop understandings of influence that lead them to cite groups in the Influence network. It is quite plausible, however, that the process works, in part, in the reverse order. If an interest group representative begins to think of another interest group that it is not connected with as influential, then it may decide to 
reach out to that group to establish a connection. For example, if Actor $\mathbf{A}$ believes that Actor $\mathbf{B}$ is an influential interest group, then $\mathbf{A}$ may seek to attract $\mathbf{B}$ as a coalition partner in order to make A's coalitions more powerful. Of course, there are limits on $\mathbf{A}^{\prime}$ 's ability to attract $\mathbf{B}$. B may not wish to work on A's issue. Or, B may believe that, as a reputedly influential actor, it can achieve more by lobbying alone than by joining a coalition with $\mathbf{A}$ (Hojnacki, 1997). Nonetheless, A may, on occasion, successfully form ties with B as a result of A's initial perception that $\mathbf{B}$ is influential. To the extent that such dynamics are present in the health policy domain, then the statistical results reported here may overestimate the effects of multiplex networks on influence, since part of what is being observed is the effect of influence on multiplex networks.

The good news is that the results of the models estimated in this article suggest that the endogenous effects of Influence on Communication, Coalition Overlap, and Issue Overlap are not severe. I estimated models both with and without endogenous parameters for influence level (i.e., indegree and outdegree). The fact that the three exogenous networks maintain their significance and positive direction regardless of whether indegree and outdegree are in the model suggests that conclusions about these parameters are robust to potential endogenous effects of influence on network structures. However, such a conclusion assumes that influence reputation develops on a global basis, rather than a local basis, as is posited in this article. Thus, in order to reach a firm conclusion on this question, it would be necessary to collect and analyze longitudinal data on influence reputation, as questions of causality in networks are always problematic when dealing with cross-sectional data (Fowler et al., 2011). Such an approach would facilitate analysis of how reputations change over time and how those changes 
correspond (or not) with changes in network structure. A dynamic model, along these lines, would be consistent with the theoretical perspective advanced in this article, that influence reputations are socially constructed through interaction in multiple networks.

\section{Conclusion}

The theory of multiplex networks and influence reputation advanced in this article offers a unified perspective on how interest groups leverage networks to make sense of influence in the policy process. Previous research on interest group politics stresses the importance of networks, but has tended to focus only on one aspect of networks. Past studies examining interest group networks explore the role of communication (e.g., Carpenter et al., 2003, 2004), coalitions (e.g., Hojnacki, 1997, 1998), and issues (e.g., Browne, 1990), but they look at these types of networks in isolation from one another, rather than in combination with one another. A multiplex analysis explicitly allows for the possibility that networks interact in ways that matter for interest group behavior.

Analysis of how interest group representatives confide in one another reveals that policy networks are densely interconnected with one another, yet offers little insight on how interest group representatives weigh some connections more or less than others. Analysis of coalitions alone is useful when interest groups formally collaborate, but fails to offer insight on the behavior of interest groups that avoid formal coalitions. Analysis of issue involvement alone is revealing when interest groups carve unambiguous issue niches, but is incomplete when groups lobby outside their issue niches and play broader roles as issue advocates. 
In contrast, a multiplex analysis of networks models the fact that groups that avoid formal coalitions may compensate by relying on a few close confidants. Groups may venture outside their issue niches because they are pressured by their collaborators to change the ways that they perform their roles as issue advocates. Even though adversaries may not communicate with one another directly, issue advocacy may require them to monitor one another's activities closely through overlapping issue networks. Interest groups that are unable to move to the center of any one type of network may be able to leverage the redundancies of multiple, overlapping networks to interpret noisy signals and craft reputations for influence.

Given the overwhelming complexity of the world of public policy making, reliance on multiplex networks is essential for interest group representatives to evaluate information that is often conflicting, ambiguous, or uncertain. This article lays the foundation for future work on interest group politics that takes into account the dependencies between communication, coalitions, and issues in understanding how interest groups manage the uncertainties of their local political environments and craft strategic responses to them. Drawing on information gleaned from multiplex networks affords groups with greater opportunities bridge structural holes in their networks (Burt, 1992) than they have when relying on information flowing through a single network.

The consequences of multiplexity are likely to be much different in predicting the strategic actions of interest groups than of evaluating interest group influence. Interest groups may be able to exploit their position between networks to amplify uncertainty on the part of their competitors in order to outflank them in the quest for influence. For example, Heaney and Lorenz (2012: 28) document precisely this strategic behavior on the part of AARP in its 
successful efforts to influence the enactment and implementation of the Medicare

Modernization Act of 2003. Clearly, a careful application of multiplexity theory requires the analyst to be sensitive to differences in the strategic uses of networks in understanding their use and value to interest groups.

While the analysis reported here speaks directly to questions in interest group politics, it can also be generalized, to some extent, in thinking about other political systems. While networks of communication, coalitions, and issues are of specific concern to interest group scholars, other kinds of multiplex networks may matter in other aspects of the policy process. For example, bureaucrats at the Food and Drug Administration (FDA) or other government agencies may rely heavily upon advice networks that provide them information about technical decisions (Carpenter 2010). The FDA's multiplex networks may include connections with other bureaucrats, scientific experts, academics, and policy advocates. While the exact model developed in this article would not apply in these cases, an analogous approach may be useful in studies of influence reputation in institutions such as the European Parliament, the United Nations, and associations of nongovernmental organizations.

\section{Acknowledgements}

Many thanks are owed to Nicole Burns for excellent research assistance. For helpful suggestions, the author is grateful to Russ Bernard, Carter Butts, Skyler Cranmer, James Fowler, Steve Goodreau, Matt Grossman, Mark Handcock, Mark Hansen, Joe Galaskiewicz, David Hunter, Lorien Jasny, Ed Laumann, David Lazer, Philip Leifeld, Geoff Lorenz, Suzanne Luft, Seth Masket, Scott McClurg, Walter Mebane, Martina Morris, Amanda Murdie, Hans Noel, Brendan 
Nyhan, Jason Owen-Smith, John Padgett, Diane Payne, Fabio Rojas, Betsy Sinclair, Jennifer Victor, Christopher Weare, three anonymous reviewers for Social Networks, the Statnet community, participants in the Networks Workshop at the University of Michigan, and participants in panels held at the 2010 Annual Meeting of the American Political Science Association, the 2010 and 2011 Annual Political Networks Conference and Workshop, and the European Science Foundation workshop on "Power, Decision Making and Social Networks" held at University College Dublin, August 25-27, 2010.

\section{References}

Bachrach, P., Baratz, M.S. 1962. Two Faces of Power. American Political Science Review 56, 947952.

Baldassarri, D., Diani, M. 2007. The Integrative Power of Civic Networks. American Journal of Sociology $113,735-780$.

Banfield, E.C. 1961. Political Influence. Free Press, New York.

Baumgartner, F.R., Berry, J.M., Hojnacki, M., Kimball, D.C., Leech, B.L. 2009. Lobbying and Policy Change: Who Wins, Who Loses, and Why. University of Chicago Press, Chicago.

Beritelli, P., Laesser, C. 2011. Power Dimensions and Influence Reputation in Tourist Destinations: Empirical Evidence from a Network of Actors and Stakeholders. Tourism Management 32, 1299-1309.

Birnbaum, J.H. 1992. The Lobbyists: How Influence Peddlers Work Their Way in Washington. Random House, New York. 
Birnbaum, J.H., Murray, A.S. 1987. Showdown at Gucci Gulch: Lawmakers, Lobbyists, and the Unlikely Triumph of Tax Reform. Random House, New York.

Borgatti, S.P., Everett, M.G., Freeman, L.C. 2011. UCINet 6.289 for Windows: Software for Social Network Analysis.

Breiger, R.L. 1974. The Duality of Persons and Groups. Social Forces 53, 181-190.

Browne, W.P. 1990. Organized Interests and their Issue Niches: A Search for Pluralism in a Policy Domain. Journal of Politics 52, 477-509.

Burt, R.S. 1992. Structural Holes: The Social Structure of Competition. Harvard University Press, Cambridge, MA.

Burt, R.S. 2005. Brokerage and Closure: An Introduction to Social Capital. Oxford University Press, Oxford, UK.

Carpenter, D.P. 2010. Reputation and Power: Organizational Image and Pharmaceutical Regulation at the FDA. Princeton University Press, Princeton, NJ.

Carpenter, D.P. 2012. Is Health Politics Different? Annual Review of Political Science 15, 287311.

Carpenter, D.P., Esterling, K.M., Lazer, D.M.J. 2003. The Strength of Strong Ties: A Model of Contact-Making in Policy Networks with Evidence from U.S. Health Politics. Rationality and Society 15:411-40.

Carpenter, D.P., Esterling, K.M., Lazer, D.M.J. 2004. Friends, Brokers, and Transitivity: Who Informs Whom in Washington Politics. Journal of Politics 66, 224-246.

Center for Responsive Politics. 2003. Political Action Committees. Available at: http://www.opensecrets .org/pacs/index.asp (accessed June 19, 2003). 
Center for Responsive Politics. 2012. Lobbying Database. Available at:

http://www.opensecrets.org/lobby/index.php (accessed February 24, 2012).

Cranmer, S.J., Desmarais, B.A. 2011. Inferential Network Analysis with Exponential Random Graph Models. Political Analysis 19, 66-86.

Dahl, R.A. 1957. The Concept of Power. Behavioral Science 2, 201-215.

Dekker, D., Krackhardt, D., Snijders, T.A.B. 2007. Sensitivity of MRQAP Tests to Collinearity and Autocorrelation Conditions. Psychometrika 72, 563-581.

DiMaggio, P.J., Powell, W.W. 1983. The Iron Cage Revisited: Institutional Isomorphism and Collective Rationality in Organizational Fields. American Sociological Review 48, 147160.

Dunbar, R.I.M. 2004. Gossip in Evolutionary Perspective. Review of General Psychology 8, 100110.

Ellwardt, L., Libianca, G., Wittek, R. 2012. Who Are the Objects of Positive and Negative Gossip at Work? A Social Network Perspective on Workplace Gossip. Social Networks 34, 193205.

Fernandez, R.M., Gould, R.V. 1994. A Dilemma of State Power: Brokerage and Influence in the National Health Policy domain. American Journal of Sociology 99, 1455-1491.

Fowler, J.H. 2006. Legislative Cosponsorship Networks in the U.S. House and Senate. Social Networks 28, 454-465.

Fowler, J.H., Heaney, M.T., Nickerson, D.W., Padgett, J.F., Sinclair, B. 2011. Causality in Political Networks. American Politics Research 39, 437-480. 
Frank, O., Strauss, D. 1986. Markov Graphs. Journal of the American Statistical Association 81, $832-842$

Galaskiewicz, J. 1979. Exchange Networks and Community Politics. Beverly Hills, CA: Sage.

Gamson, W.A. 1966. Reputation and Resources in Community Politics. American Journal of Sociology 72, 121-131.

Goldstein, Kenneth M., Michael Franz, and Travis Ridout. 2002. Political Advertising in 2000. Combined File [dataset]. Final release. Madison, WI: The Department of Political Science at The University of Wisconsin-Madison and The Brennan Center for Justice at New York University.

Gondal, N. 2011. The Local and Global structure of Knowledge Production in an Emergent Research Field: An Exponential Random Graph Analysis. Social Networks 33, 20-30.

Goodreau, S.M., Handcock, M.S., Hunter, D.R., Butts, C.T., Morris, M. 2008. A statnet Tutorial. Journal of Statistical Software 24, 9.

Goodreau, S.M., Kitts, J.A., Morris, M. 2009. Birds of a Feather, or Friend of a Friend? Using Exponential Random Graph Models to Investigate Adolescent Social Networks. Demography 46, 103-125.

Gould, R.V. 1991. Multiple Networks and Mobilization in the Paris Commune, 1871. American Sociological Review 56, 716-729.

Granovetter, M. 1973. The Strength of Weak Ties. American Journal of Sociology 78, 1360-1380. Granovetter, M. 1985. Economic Action and Social Structure: The Problem of Embeddedness. American Journal of Sociology 91, 481-510. 
Grossman, M., Dominguez, C.B.K. 2009. Party Coalitions and Interest Group Networks. American Politics Research 37, 767-800.

Heaney, M.T. 2004. Outside the Issue Niche: The Multidimensionality of Interest Group Identity. American Politics Research 32, 611-651.

Heaney, M.T. 2006. Brokering Health Policy: Coalitions, Parties, and Interest Group Influence. Journal of Health Politics, Policy and Law 31, 887-944.

Heaney, M.T., Rojas, F. 2007. Partisans, Nonpartisans, and the Antiwar Movement in the United States. American Politics Research 35, 431-464.

Heaney, M.T., Lorenz, G.M. 2012. Coalition Portfolios and Interest Group Influence over the Policy Process. Paper Presented at the Annual Meeting of the American Political Science Association, New Orleans, Louisiana, August 30-September 2. Available at: http://papers.ssrn.com/sol3/papers.cfm?abstract_id=2107376 (accessed November 2, 2012).

Heaney, M.T., Masket, S.E., Miller, J.M., Strolovitch, D.Z. 2012. Polarized Networks: The Organizational Affiliations of National Party Convention Delegates. American Behavioral Scientist 56, 1654-1676.

Heclo, H. 1978. Issue Networks and the Executive Establishment. In: King, A. (Ed.), The New American Political System. American Enterprise Institute, Washington, DC, pp. 87-124.

Hojnacki, M. 1997. Interest Groups' Decisions to Join Alliances or Work Alone. American Journal of Political Science 41, 61-87.

Hojnacki, M. 1998. Organized Interests' Advocacy Behavior in Alliances. Political Research Quarterly 51, 437-459. 
Hojnacki, M., Kimball, D.C., Baumgartner, F.R., Berry, J.M., Leech, B.L. 2012. Studying

Organizational Advocacy and Influence: Reexamining Interest Group Research. Annual Review of Political Science 15, 379-99.

Holyoke, T.T. 2011. Competitive Interests: Competition and Compromise in American Interest Group Politics. Georgetown University Press, Washington, DC.

Hula, K.W. 1999. Lobbying Together: Interest Group Coalitions in Legislative Politics. Georgetown University Press, Washington, DC.

Hunter, D.R., Goodreau, S.M., Handcock, M.S. 2008. Goodness of Fit of Social Network Models. Journal of the American Statistical Association 103, 248-258.

Hunter, D.R., Handcock, M.S., Butts, C.T., Goodreau, S.M., Morris, M. 2008. ergm: A Package to Fit, Simulate and Diagnose Exponential-Family Models for Networks. Journal of Statistical Software 24, 3.

Krackhardt, D. 1987. QAP Partialling as a Test of Spuriousness. Social Networks 9, 171-186.

Krackhardt, D. 1990. Assessing the Political Landscape: Structure, Cognition, and Power in Organizations. Administrative Science Quarterly, 35: 342-369.

Krackhardt, D. 1992. The Strength of Strong Ties: The Importance of Philos in Organizations. In: N. Nohria, N., Eccles, R. (Eds.), Networks and Organizations: Structure, Form, and Action. Harvard Business School Press, Boston, MA, pp. 216-239.

Landau, M. 1969. Redundancy, Rationality, and the Problem of duplication and Overlap. Public Administration Review 29, 346-358.

Lang, G.E., Lang, K. 1988. Recognition and Renown: The survival of Artistic Reputation. American Journal of Sociology 94, 79-109. 
Laumann, E.O., Knoke, D. 1987. The Organizational State: Social Choice in National Policy Domains. University of Wisconsin Press, Madison, WI.

Laumann, E.O., Marsden, P.V., Galaskiewicz, J. 1977. Community-Elite Influence Structures:

Extension of a Network Approach. American Journal of Sociology 83, 594-631.

Laumann, E.O., Marsden, P.V., Prensky, D. 1989. The Boundary Specification Problem in

Network Analysis. In: L. Freeman, D.R. White, A.K. Romney (Eds.), Research Methods in Social Network Analysis. George Mason University Press, Fairfax, VA, pp. 61-87.

Lawrence, B.S. 2006. Organizational Reference Groups: A Missing Perspective on Social Context. Organization Science 17, 80-100.

Leifeld, P., Schneider, V. 2012. Information Exchange in Policy Networks. American Journal of Political Science 56, 731-44.

LexisNexis. 2002. CIS Index to Publications of the United States Congress. Available at: http://www.lexisnexis.com/academic/3cis/cisl/cis-index.asp (accessed November 15, 2002).

List, J.A. 2006. The Behavioralist Meets the Market: Measuring Social Preferences and Reputation Effects in Actual Transactions. Journal of Political Economy 114: 1-37.

Loomis, B. 1986. Coalitions of Interests: Building Bridges in the Balkanized State. In: Interest Group Politics, 2nd ed., ed. Allan J. Cigler and Burdett Loomis, 258 - 274. Washington, DC: CQ Press.

Mahoney, C. 2008. Brussels versus the Beltway: Advocacy in the United States and the European Union. Washington, DC: Georgetown University Press. 
McPherson, M., Smith-Lovin, L., Cook, J.M. 2001. Birds of a Feather: Homophily in Social Networks. Annual Review of Sociology 27, 415-444.

Murdie, Amanda, and David R. Davis. 2012. Looking in the Mirror: Comparing INGO Networks Across Issue Areas. Review of International Organizations 7, 177-202

Nelson, D., Yackee, S.W. 2012. Lobbying Coalitions and Government Policy Change: An Analysis of Federal Agency Rulemaking. Journal of Politics 74, 339-53.

Noel, H., Nyhan, B. 2011. The "Unfriending" Problem: The Consequences of Homophily in Friendship Retention for Causal Estimates of Social Influence. Social Networks 33, 211218.

Padgett, J.F., Ansell, C.K. 1993. Robust Action and the Rise of the Medici, 1400-1434. American Journal of Sociology 98, 1259-1319.

Padgett, J.F., Powell, W.W. 2012. The Emergence of Organizations and Markets. Princeton: Princeton University Press.

Patashnik, E.M. 2008. Reforms at Risk: What Happens After Major Policy Changes Are Enacted. Princeton University Press, Princeton, NJ.

Porter, M.A., Mucha, P.J., Newman, M.E.J., Warmbrand, C.M. 2005. A Network Analysis of Committees in the U.S. House of Representatives. Proceedings of the National Academy of Sciences 102, 7057-7062.

Price, K., Gioia, D.A. 2008. The Self-Monitoring Organization: Minimizing Discrepancies among Differing Images of Organizational Identity. Corporate Reputation Review 11, 208-221. Robins, G., Snijders, T., Wang, P., Handcock, M., Pattison, P. 2007. Recent Developments in Exponential Random Graph ( $p^{*}$ ) for Social Networks. Social Networks 29, 192-215. 
Schwarz, G. 1978. Estimating the Dimension of a Model. Annals of Statistics 6, 461-464.

Simpson, B., Markovsky, B., Steketee, M. 2011. Network Knowledge and the Use of Power. Social Networks 33, 172-176.

Smith, R.A. 1995. Interest Group Influence in the U.S. Congress. Legislative Studies Quarterly 20, 89-139.

Snijders, T.A.B. 2002. Markov Chain Monte Carlo Estimation of Exponential Random Graph Models. Journal of Social Structure 3, 2. Available at: http://www.cmu.edu/joss/content/articles/volume3/Snijders.pdf (Accessed June 1, 2002).

Snijders, T.A.B., Pattison, P.E., Robins, G.L., Handcock, M.S. 2006. New Specifications for Exponential Random Graph Models. Sociological Methodology 36, 99-153.

Stuart, T.E., Hoang, H., Hybels, R.C. 1999. Interorganizational Endorsements and the Performance of Entrepreneurial Ventures. Administrative Science Quarterly 44, 315349.

Tauberer, J. 2011. Kill Bill: How Many Bills Are There? How Many Are Enacted? Available at: http://www.govtrack.us/blog/2011/08/04/kill-bill-how-many-bills-are-there-how-manyare-enacted/ (Accessed February 24, 2012).

U.S. Senate, Office of Public Records. 2002. Lobby Filing Disclosure Program. Available at: http://sopr.senate.gov/ (accessed October 30, 2002).

U.S. Senate, Office of Public Records. 2003. Lobby Filing Disclosure Program. Available at: http://sopr.senate.gov/ (accessed September 30, 2004).

Verbrugge, L.M. 1979. Multiplexity in Adult Friendships. Social Forces 57, 1286-1309. 
White, Harrison C. 2008. Identity and Control: How Social Formations Emerge, $2^{\text {nd }}$ ed. Princeton University Press, Princeton, NJ.

Wedeen, L. 1998. Acting “As If': Symbolic Politics and Social Control in Syria. Comparative Studies in Society and History 40, 503-523.

Weible, C.M. 2005. Beliefs and Perceived Influence in a Natural Resource Conflict: An Advocacy Coalition Approach to Policy Networks. Political Research Quarterly 58: 461-475.

Wolfinger, R.E. 1960. Reputation and Reality in the Study of "Community Power." American Sociological Review 25, 636-644. 
Table 1. Network Descriptions

Network

Influence

Communication
Definition, Interview Question, and Data Sources
Interview Question: As I have indicated, all of the organizations on this list are very active in the national health policy area. But I would now like you to circle the codes of those organizations which stand out as especially influential in formulating national health care policy.

Data Source: Author interviews with 168 interest group representatives in Washington, DC, conducted in 2003.
Definition: If A cites B as a partner for "occasional meetings and other communications," then the edge takes the value of 1 ; If A cites B as a partner for "regular meetings and other communications, then the edge takes the value of 2; otherwise the edge takes the value of 0 .

Interview Question: Please look at the list of interest groups in Card C. Please indicate the nature of your relationship with each group on health care issues during the 107th and 108th Congresses. Do you have: Occasional meetings and other communications; Regular meetings and other communications.

Data Source: Author interviews with 168 interest group representatives in Washington, DC, conducted in 2003.

Definition: The edge between A and B takes the value of the number of health care coalitions that the two interest groups had in common during the $107^{\text {th }}$ and $108^{\text {th }}$ Congress.

Interview Question: Please look at the list of coalitions in Card B. For each of these coalitions, please indicate whether your organization has been a member of this coalition in the past or is currently a member of the coalition. If your organization has never been a member of this coalition, please leave this part blank. If there are any other health-related coalitions of which your organization is a member, please indicate this under "other coalitions."

Data Sources: Author interviews with 168 interest group representatives in Washington, DC, conducted in 2003. Organizational membership lists provided by coalition leaders. The network data were generated from the actual membership lists, rather than the responses to the interview question. The initial list of 77 coalitions was generated from interviews with 95 congressional staff members working on health policy issues 
Table 1 Continued. Network Descriptions

Issue Overlap

Definition: The edge between A and B takes the value of the number of health care issues that the two interest groups had in common during the $107^{\text {th }}$ and $108^{\text {th }}$ Congress, based on a designation of those issues as "major" by the respondents.

Interview Question: Please look at the list of health care issues in Card A. For each issue, can you tell me, was this issue a major or a minor priority for your organization during the 107th and 108th Congresses?

Data Sources: Author interviews with 168 interest group representatives in Washington, DC, conducted in 2003. The initial list of 40 issues was generated from the census of articles appearing in CQ Weekly, 2001-2002. 
Table 2. Network Properties

\begin{tabular}{|c|c|c|c|c|}
\hline Network Property & Influence & Communication & $\begin{array}{c}\text { Coalition } \\
\text { Overlap }\end{array}$ & Issue Overlap \\
\hline Directionality & Directed & Directed & Undirected & Undirected \\
\hline Edge Values & Binary & Valued & Valued & Valued \\
\hline Node Count & 168 & 168 & 168 & 168 \\
\hline Edge Count & 3,384 & 5,142 & 9,118 & 21,234 \\
\hline Mean Degree & 20.429 & 30.869 & 55.173 & 127.357 \\
\hline Degree Standard Deviation & 26.172 & 26.704 & 34.525 & 35.852 \\
\hline Mean Edge Value & 0.121 & 0.265 & 0.709 & 2.573 \\
\hline Edge Value Standard Deviation & 0.326 & 0.599 & 1.409 & 2.527 \\
\hline Density & 0.121 & 0.183 & 0.325 & 0.757 \\
\hline Centralization (betweenness) & 0.113 & 0.043 & 0.016 & 0.002 \\
\hline Connectedness & 0.953 & 1.000 & 0.807 & 0.930 \\
\hline Reciprocity & 0.791 & 0.830 & N/A & N/A \\
\hline Transitivity & 0.456 & 0.409 & 0.677 & 0.878 \\
\hline
\end{tabular}

Estimation was conducted using the statnet package in $R$ (Goodreau et al., 2008). Reciprocity is not calculated for the Coalition Overlap and Issue Overlap networks because, as undirected affiliation networks, they have perfect reciprocity by definition. 
Table 3. Network Correlations

\begin{tabular}{lccc}
\hline & Communication & Coalition Overlap & Issue Overlap \\
\hline Influence & $0.140^{* * *}$ & $0.092^{* * *}$ & $0.127^{* * *}$ \\
Communication & $0.367^{* * *}$ & $0.303^{* * *}$ \\
Coalition Overlap & & $0.288^{* * *}$ \\
\hline
\end{tabular}

$* * * p \leq 0.001 ; * * p \leq 0.010 ;{ }^{*} p \leq 0.050$.

The Quadratic Assignment Procedure (QAP) was used to generate correlations and tests of statistical significance (Krackhardt, 1987). Estimation was performed in UCINet 6.289 (Borgatti et al., 2011). 
Table 4. Concordance in Citations across Networks

Then also tied in...

\begin{tabular}{|c|c|c|c|c|c|}
\hline \multicolumn{2}{|c|}{ 1. Bivariate Concordance } & \multirow[t]{2}{*}{ Influence } & Communication & $\begin{array}{c}\text { Coalition } \\
\text { Overlap }\end{array}$ & $\begin{array}{c}\text { Issue } \\
\text { Overlap }\end{array}$ \\
\hline & Influence & & $0.322 * * *$ & $0.440 * * *$ & $0.837 * * *$ \\
\hline \multirow[t]{3}{*}{ If tied in... } & Communication & $0.210 * * *$ & & $0.605^{* * *}$ & $0.898 * * *$ \\
\hline & Coalition Overlap & $0.163^{* * *}$ & $0.344^{* * *}$ & & $0.877^{* * *}$ \\
\hline & Issue Overlap & $0.133^{* * *}$ & $0.219 * * *$ & $0.376^{* * *}$ & \\
\hline
\end{tabular}

Then also tied in...

2. Higher-Order Concordance

Influence

$\begin{array}{ll}\text { Communication and Coalition Overlap } & 0.231^{* * *}\end{array}$

If tied in... Communication and Issue Overlap $\quad 0.223^{* * *}$

Coalition Overlap and Issue Overlap $\quad 0.175^{* * *}$

Communication, Coalition Overlap, and Issue Overlap $\quad 0.237^{* * *}$

$* * * \mathrm{p} \leq 0.001 ; * * \mathrm{p} \leq 0.010 ;{ }^{*} \mathrm{p} \leq 0.050$.

Table entries are the conditional probably of being tied in the network listed in the column given that an interest group dyad is tied in the network listed in the row. Statistical significance was determined using a standard t test. 
Table 5. Exponential Random Graph Models for Influence Network

\begin{tabular}{|c|c|c|c|c|c|c|}
\hline \multirow{4}{*}{$\begin{array}{l}\text { Exogenous Parameters } \\
\text { Communication Network }\end{array}$} & \multirow{2}{*}{$\begin{array}{c}\text { Baseline } \\
\text { Model } \\
(1)\end{array}$} & \multicolumn{4}{|c|}{ Baseline Plus One Network Model } & \multirow{2}{*}{$\begin{array}{c}\text { Multiplex } \\
\text { Full Model } \\
\text { (6) }\end{array}$} \\
\hline & & $(2)$ & (3) & (4) & (5) & \\
\hline & & \multicolumn{5}{|c|}{ Coefficient / (Standard Error) / [MCMC Standard Error] } \\
\hline & & $0.331 * * *$ & & & $0.369 * * *$ & $0.255^{* * *}$ \\
\hline & & $(0.032)$ & & & $(0.028)$ & $(0.037)$ \\
\hline & & {$[0.006]$} & & & {$[0.001]$} & {$[0.007]$} \\
\hline \multirow[t]{3}{*}{ Coalition Overlap Network } & & & $0.103 * * *$ & & $0.031 * *$ & $0.053^{* * *}$ \\
\hline & & & $(0.013)$ & & $(0.012)$ & $(0.015)$ \\
\hline & & & [0.001] & & {$[0.000]$} & {$[0.001]$} \\
\hline \multirow[t]{3}{*}{ Issue Overlap Network } & & & & $0.063^{* * *}$ & $0.067 * * *$ & $0.035^{* * *}$ \\
\hline & & & & $(0.006)$ & $(0.005)$ & $(0.007)$ \\
\hline & & & & {$[0.000]$} & {$[0.000]$} & {$[0.000]$} \\
\hline \multirow[t]{3}{*}{ Same Organizational Type } & $0.261^{* * *}$ & $0.226 * * *$ & $0.206 * * *$ & $0.300 * * *$ & 0.004 & $0.183^{* * *}$ \\
\hline & $(0.054)$ & $(0.055)$ & $(0.054)$ & $(0.054)$ & $(0.044)$ & $(0.055)$ \\
\hline & {$[0.015]$} & {$[0.011]$} & {$[0.012]$} & {$[0.012]$} & {$[0.000]$} & {$[0.002]$} \\
\hline \multirow[t]{3}{*}{ Similar Partisan Ties } & 0.022 & -0.045 & 0.037 & 0.021 & $-0.377 * * *$ & 0.035 \\
\hline & $(0.045)$ & $(0.046)$ & $(0.045)$ & $(0.046)$ & (0.039) & $(0.047)$ \\
\hline & $(0.008)$ & {$[0.002]$} & {$[0.002]$} & {$[0.003]$} & {$[0.000]$} & {$[0.001]$} \\
\hline \multirow[t]{3}{*}{ Similar Lobbying activity } & $0.278^{* * *}$ & $0.181^{*}$ & $0.294^{* * *}$ & $0.305^{* * *}$ & $0.807 * * *$ & $0.250 * *$ \\
\hline & $(0.083)$ & $(0.081)$ & $(0.082)$ & $(0.082)$ & $(0.059)$ & $(0.079)$ \\
\hline & {$[0.003]$} & {$[0.002]$} & {$[0.003]$} & {$[0.003]$} & {$[0.000]$} & {$[0.002]$} \\
\hline \multirow[t]{3}{*}{ Both Have PAC } & $-0.125^{*}$ & -0.060 & -0.080 & -0.115 & $0.110 * * *$ & $-0.068 * *$ \\
\hline & $(0.060)$ & $(0.059)$ & $(0.060)$ & $(0.060)$ & $(0.016)$ & $(0.022)$ \\
\hline & {$[0.002]$} & {$[0.002]$} & {$[0.002]$} & {$[0.002]$} & {$[0.000]$} & {$[0.000]$} \\
\hline \multirow[t]{3}{*}{ Both Make Independent Expenditures } & -0.034 & -0.176 & 0.010 & -0.318 & $0.752 * * *$ & -0.125 \\
\hline & (0.191) & $(0.192)$ & (0.192) & $(0.180)$ & $(0.062)$ & $(0.075)$ \\
\hline & {$[0.007]$} & {$[0.004]$} & {$[0.003]$} & {$[0.003]$} & {$[0.000]$} & {$[0.000]$} \\
\hline \multirow[t]{3}{*}{ Both Have Downtown Office } & 0.084 & 0.066 & 0.035 & 0.081 & $0.403 * * *$ & 0.012 \\
\hline & $(0.046)$ & $(0.044)$ & $(0.043)$ & $(0.042)$ & (0.013) & $(0.015)$ \\
\hline & [0.002] & [0.002] & [0.001] & [0.001] & {$[0.000]$} & {$[0.000]$} \\
\hline
\end{tabular}

Table 5 Continued on Next Page 
Table 5 Continued. Exponential Random Graph Models for Influence Network

\begin{tabular}{|c|c|c|c|c|c|c|}
\hline \multicolumn{7}{|l|}{ Endogenous Parameters } \\
\hline \multirow[t]{3}{*}{ Edges } & $-5.129 * * *$ & $-5.187^{* * *}$ & $-5.187 * * *$ & $-5.271 * * *$ & $-2.495 * * *$ & $-5.281 * * *$ \\
\hline & $(0.008)$ & $(0.010)$ & $(0.008)$ & $(0.009)$ & $(0.006)$ & $(0.009)$ \\
\hline & {$[0.000]$} & {$[0.000]$} & {$[0.000]$} & {$[0.000]$} & {$[0.000]$} & {$[0.000]$} \\
\hline \multirow[t]{3}{*}{ One Edgewise Shared Partner } & $-0.197 * * *$ & $-0.184 * * *$ & $-0.190 * * *$ & $-0.184 * * *$ & $-0.288 * * *$ & $-0.162 * * *$ \\
\hline & $(0.0334)$ & $(0.030)$ & $(0.033)$ & $(0.030)$ & $(0.061)$ & $(0.026)$ \\
\hline & {$[0.000]$} & {$[0.000]$} & {$[0.000]$} & {$[0.000]$} & {$[0.000]$} & {$[0.000]$} \\
\hline \multirow[t]{3}{*}{ Two Edgewise Shared Partners } & $-0.153 * * *$ & $-0.145 * * *$ & $0.146 * * *$ & $-0.146 * * *$ & $-0.316 * * *$ & $-0.137 * * *$ \\
\hline & $(0.021)$ & $(0.024)$ & $(0.020)$ & $(0.023)$ & $(0.062)$ & $(0.023)$ \\
\hline & {$[0.000]$} & {$[0.000]$} & {$[0.000]$} & $(0.000)$ & {$[0.000]$} & {$[0.000]$} \\
\hline \multirow[t]{3}{*}{ Influence Indegree of $\boldsymbol{A}$} & $0.047 * * *$ & $0.047 * * *$ & $0.047 * * *$ & $0.047^{* * *}$ & & $0.046 * * *$ \\
\hline & $(0.001)$ & $(0.000)$ & $(0.000)$ & $(0.000)$ & & $(0.000)$ \\
\hline & {$[0.000]$} & {$[0.000]$} & {$[0.000]$} & {$[0.000]$} & & {$[0.000]$} \\
\hline \multirow{3}{*}{ Influence Outdegree of $\boldsymbol{A}$} & $0.064 * * *$ & $0.065 * * *$ & $0.065 * * *$ & $0.064 * * *$ & & $0.064 * * *$ \\
\hline & 0.000 & $(0.000)$ & $(0.000)$ & $(0.000)$ & & $(0.000)$ \\
\hline & {$[0.000]$} & {$[0.000]$} & {$[0.000]$} & {$[0.000]$} & & {$[0.000]$} \\
\hline $\mathrm{N}$ (dyads) & 28,056 & 28,056 & 28,056 & 28,056 & 28,056 & 28,056 \\
\hline Markov Chain Monte Carlo (MCMC) Samples & $1,000,000$ & $1,000,000$ & $1,000,000$ & $1,000,000$ & $1,000,000$ & $1,000,000$ \\
\hline Akaike Information Criterion (AIC) & 13,479 & 13,380 & 13,429 & 13,431 & 19,102 & 13,355 \\
\hline Bayesian Information Criterion (BIC) & 13,570 & 13,479 & 13,528 & 13,529 & 19,201 & 13,471 \\
\hline
\end{tabular}

$* * * \mathrm{p} \leq 0.001 ; * * \mathrm{p} \leq 0.010 ;{ }^{*} \mathrm{p} \leq 0.050$.

Estimation was conducted using the ergm package in R (Hunter, Handcock, et al., 2008). 
Table 6. Double Semi-Partialing Multiple Regression Quadratic Assignment Procedure for Influence Network

\begin{tabular}{|c|c|c|c|c|c|}
\hline & \multirow{2}{*}{$\begin{array}{l}\text { Homophily } \\
\text { Only Model } \\
\text { (7) }\end{array}$} & \multicolumn{3}{|c|}{ Homophily Plus One Network Model } & \multirow{2}{*}{$\begin{array}{c}\text { Multiplex } \\
\text { Full Model } \\
\text { (11) }\end{array}$} \\
\hline & & (8) & (9) & (10) & \\
\hline & \multicolumn{5}{|c|}{ Standardized Coefficient / (Standard Error) } \\
\hline Communication Network & & $\begin{array}{c}0.162 * * * \\
(0.025)\end{array}$ & & & $\begin{array}{c}0.096 * * * \\
(0.010)\end{array}$ \\
\hline Coalition Overlap Network & & & $\begin{array}{c}0.082 * * * \\
(0.012)\end{array}$ & & $\begin{array}{c}0.048^{* *} \\
(0.011)\end{array}$ \\
\hline Issue Overlap Network & & & & $\begin{array}{c}0.063 * * * \\
(0.014)\end{array}$ & $\begin{array}{l}0.038^{*} \\
(0.013)\end{array}$ \\
\hline Same Organizational Type & $\begin{array}{c}0.016 \\
(0.008)\end{array}$ & $\begin{array}{c}0.022 \\
(0.019)\end{array}$ & $\begin{array}{c}0.008 \\
(0.008)\end{array}$ & $\begin{array}{c}0.013 \\
(0.008)\end{array}$ & $\begin{array}{c}-0.001 \\
(0.008)\end{array}$ \\
\hline Similar Partisan Ties & $\begin{array}{c}-0.061^{* * *} \\
(0.010)\end{array}$ & $\begin{array}{c}-0.050^{*} \\
(0.025)\end{array}$ & $\begin{array}{c}-0.062^{* * *} \\
(0.010)\end{array}$ & $\begin{array}{c}-0.058^{* * *} \\
(0.010)\end{array}$ & $\begin{array}{c}-0.058^{* * *} \\
(0.009)\end{array}$ \\
\hline Similar Lobbying activity & $\begin{array}{c}0.102 * * * \\
(0.024)\end{array}$ & $\begin{array}{l}-0.037 \\
(0.060)\end{array}$ & $\begin{array}{c}0.101^{* * *} \\
(0.024)\end{array}$ & $\begin{array}{c}0.103^{* * *} \\
(0.024)\end{array}$ & $\begin{array}{c}0.095^{* * *} \\
(0.022)\end{array}$ \\
\hline Both Have PAC & $\begin{array}{c}0.023 \\
(0.018)\end{array}$ & $\begin{array}{c}0.008 \\
(0.047)\end{array}$ & $\begin{array}{c}0.024 \\
(0.018)\end{array}$ & $\begin{array}{c}0.022 \\
(0.018)\end{array}$ & $\begin{array}{c}0.021 \\
(0.017)\end{array}$ \\
\hline Both Make Independent Expenditures & $\begin{array}{c}0.063 * * * \\
(0.041)\end{array}$ & $\begin{array}{c}0.029 \\
(0.100)\end{array}$ & $\begin{array}{c}0.060^{* * *} \\
(0.041)\end{array}$ & $\begin{array}{c}0.060 * * * \\
(0.041)\end{array}$ & $\begin{array}{c}0.057^{* *} \\
(0.039)\end{array}$ \\
\hline Both Have Downtown Office & $\begin{array}{c}0.069 * * \\
(0.018)\end{array}$ & $\begin{array}{c}0.014 \\
(0.029)\end{array}$ & $\begin{array}{c}0.062^{* *} \\
(0.017)\end{array}$ & $\begin{array}{c}0.068^{* *} \\
(0.017)\end{array}$ & $\begin{array}{c}0.063^{* *} \\
(0.017)\end{array}$ \\
\hline Intercept & $\begin{array}{c}0.000 \\
(0.000)\end{array}$ & $\begin{array}{c}0.000 \\
(0.000)\end{array}$ & $\begin{array}{c}0.000 \\
(0.000)\end{array}$ & $\begin{array}{c}0.000 \\
(0.000)\end{array}$ & $\begin{array}{c}0.000 \\
(0.000)\end{array}$ \\
\hline $\mathrm{N}$ (dyads) & 28,056 & 28,056 & 28,056 & 28,056 & 28,056 \\
\hline Number of Permutations & 2,000 & 2,000 & 2,000 & 2,000 & 2,000 \\
\hline Adjusted $\mathrm{R}^{2}$ & 0.031 & 0.032 & 0.037 & 0.035 & 0.048 \\
\hline
\end{tabular}

$* * * p \leq 0.001 ; * * p \leq 0.010 ;{ }^{*} p \leq 0.050$.

Estimation was performed in UCINet 6.289 (Borgatti et al., 2011). 
Figure 1. Influence Network

A. Complete Influence Network

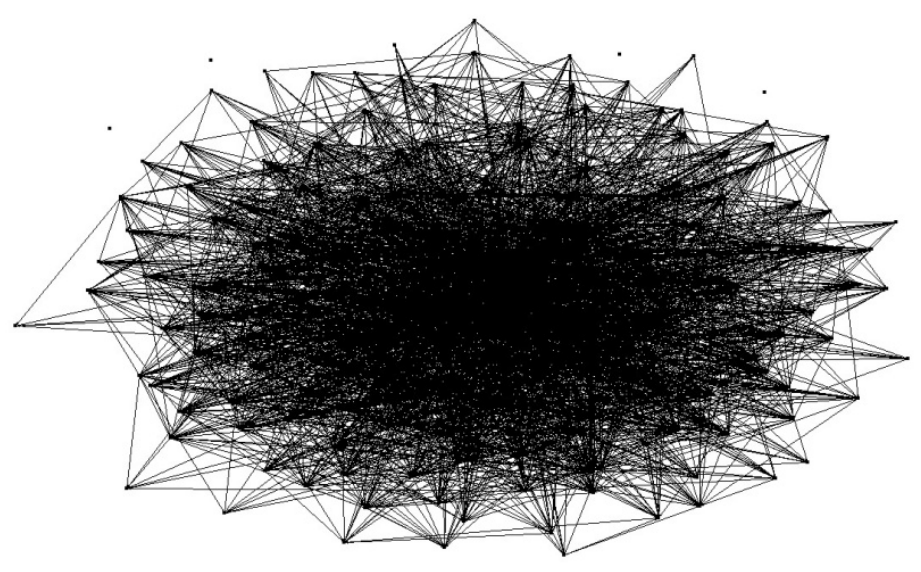

B. Influence Citations to a Leading Actor

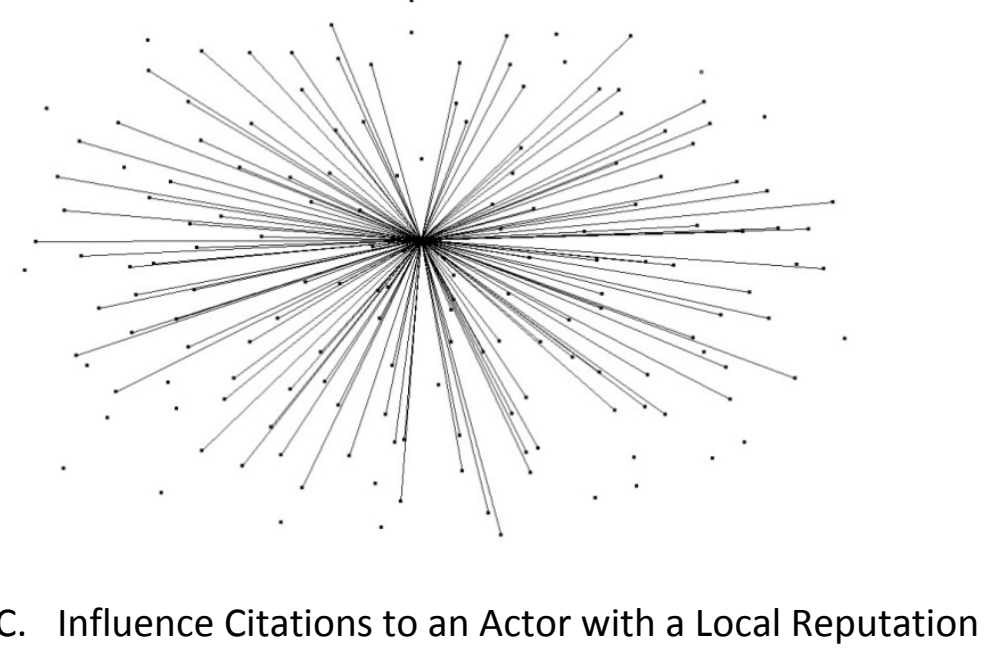


Figure 2. Uniplex and Multiplex Networks for Random Sample of 25 Nodes

A. Influence Network

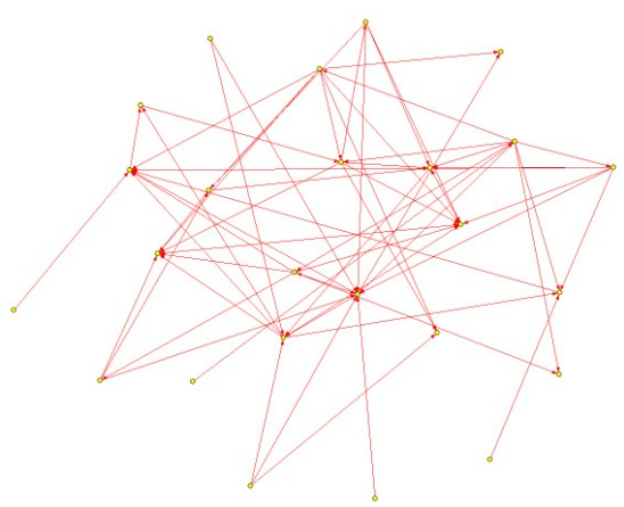

B. Communication Network

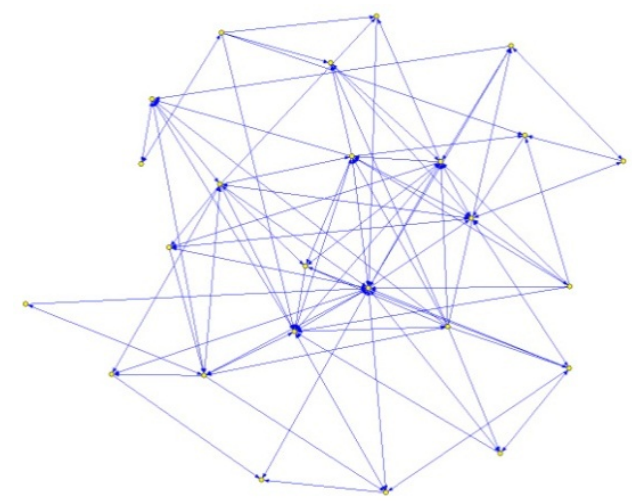

C. Influence and Communication Networks Combined

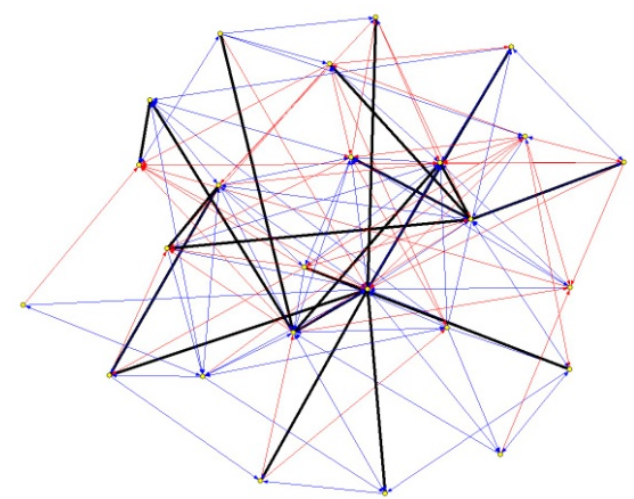

Red lines denote influence citations. Blue lines denote communication citations. Black lines denote both influence and communication 
Figure 3. Goodness of Fit for the Multiplex Full Model
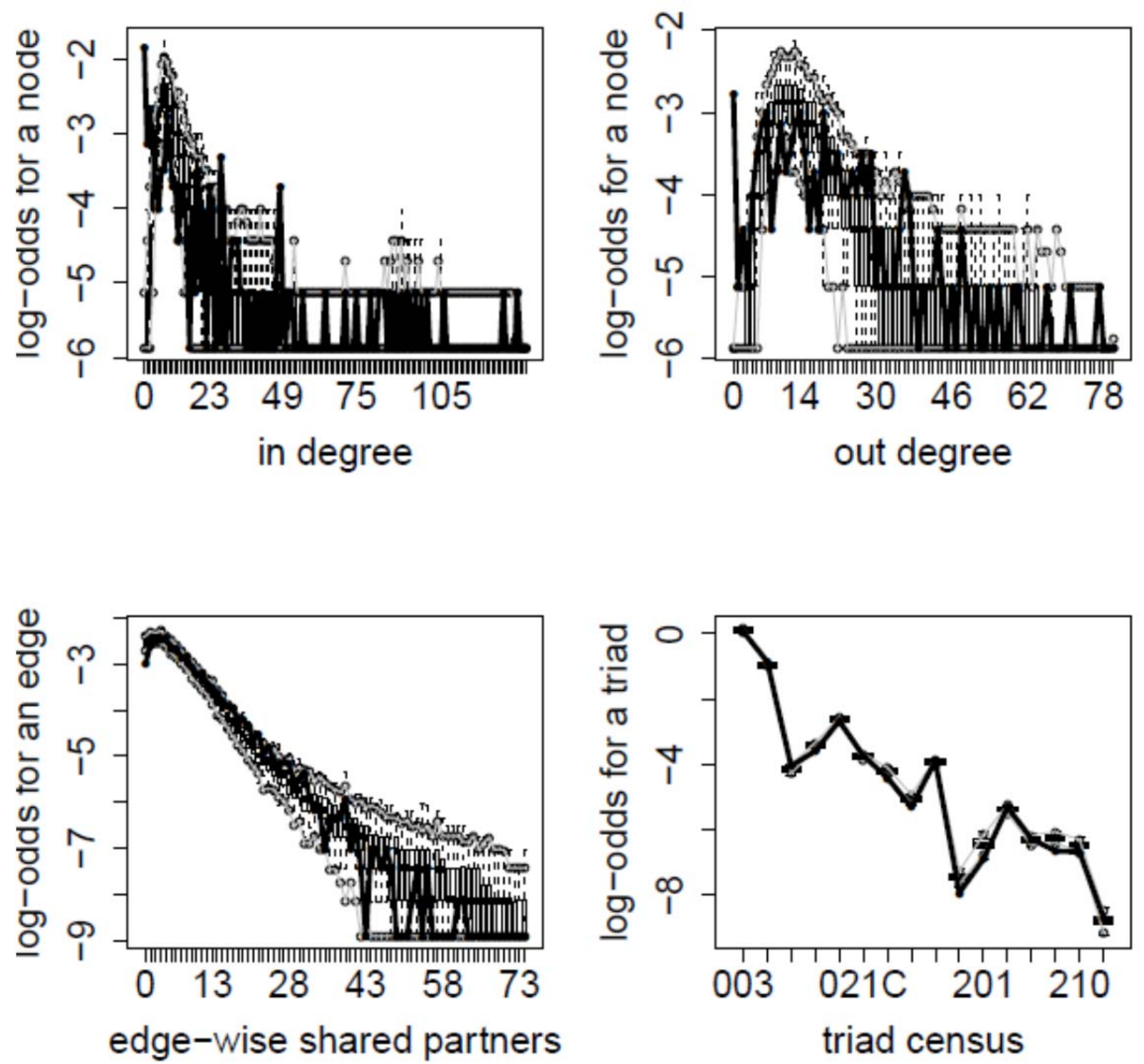